\title{
LA BIOGRAFÍA COMO OBJETO DE INVESTIGACIÓN EN EL ÁMBITO UNIVERSITARIO. REFLEXIONES SOBRE UN RETORNO
}

\section{Antonio Carreras Panchón}

Universidad de Salamanca

\begin{abstract}
RESUMEN
Se plantea una revisión de la investigación historiográfica en el tema de las biografías y su presencia en el mundo académico, las ventajas y las limitaciones, las luces y las sombras del llamado paradigma moderno de la biografía.
\end{abstract}

PALABRAS CLAVE: Biografía, historiografía.

\section{SUMMARY}

The aim of the article is to revise the historiographical research on biographies and their place in the academic world. The article also considers their advantages and limits, and the light and the darkness of the new biographical paradigm.

KEY WORDS: Biography, historiography.

\section{Del DENUESTO A LA REIVINDICACIÓN}

En un coloquio celebrado en mayo de 1985 sobre los problemas y los métodos de la biografía - llamo la atención sobre la antigüedad ya de la fechase señalaba que no era dar prueba de una gran sagacidad constatar que un viento de biografía soplaba en la historia. En aquellos años, ya un poco lejanos, se justificaba ese renacimiento como un retorno de lo irracional en tanto que elemento explicativo de la marcha de los acontecimientos. La rehabilitación del sujeto, el abandono de las explicaciones reduccionistas, la respuesta a la masificación serían también algunos de los elementos que, para otros auto- 
res, explicaban esta revitalización de una de las formas de relato histórico más antiguas y también más denostadas ${ }^{1}$.

Hace apenas un año una revisión del panorama editorial español descubría como la biografía histórica había sido un verdadero filón económico de una industria en lamentación permanente por sus bajos rendimientos y beneficios. $\mathrm{Su}$ autor llamaba la atención sobre algunas obras presentadas como biográficas - otra cosa es que puedan incluirse en la más canónica denominación del género- de Fernández Alvarez, John Elliot, o Paul Preston como responsables de grandes éxitos editoriales ${ }^{2}$. Que no son solo las biografías de políticos las responsables esos brillantes resultados comerciales lo afirmaba también Helge Kragh en su Introducción a la historia de la ciencia, cuando reconocía que las biografías "son la única forma de literatura de historia de la ciencia que logran convertirse en superventas $)^{3}$. Y entre nosotros Sánchez Ron no podía menos de reconocer también, en una revisión historiográfica de 1996, esta buena salud editorial de las biografías ${ }^{4}$.

Desde aquel retorno de los años ochenta se han producido acontecimientos que es casi ocioso recordar aquí. Mencionaré solamente dos: el desmantelamiento ideológico que supuso la caída de las llamadas «democracias populares» y la consiguiente reafirmación alternativa de que sólo los principios del liberalismo económico garantizaban tanto un ejercicio real de las libertades políticas, como una racional ordenación del mercado, que extendería al mayor número de sujetos el acceso al progreso y la riqueza. Ya sé que ésta es una simplificación reduccionista pero no conviene olvidar que en la evolución ideológica posterior —incluida la historiográfica - mensajes sobremanera esquemáticos y aún elementales se han empleado tanto en los medios de comunicación como en reflexiones pretendidamente más refinadas.

1 TORRES, F. (1985), «Du champ des Annales à la biographie: réflexions sur le retour d'un genre», Problèmes et méthodes de la biographie. Paris, 141-148; MAdELÉnAT, D. (1985), «Situation et signification de la biographie en 1985», Problèmes et méthodes de la biographie. Paris, 129-139.

2 Vila San Juan, S. (2003), Pasando página. Autores y editores en la España democrática, Barcelona, 563.

3 KRAGH, H. (1989), Introducción a la historia de la ciencia, Barcelona, 220. En el mismo sentido se expresaba unos años antes HANKINS, T. (1979), «In defense of biography, the use of biography in the history of science», History of Science, 18, 1-6.

4 SÁnchez Ron, J.M. (1996), «Ciencia e historia: el caso de la física». En Olabarri, I., CASPISTEGUI, F. (Eds.), La «nueva» historia cultural: la influencia del postestructuralismo y el auge de la interdisciplinariedad, Madrid, 83-113. 
Por eso en una revisión como ésta es preciso volver a recordar que ha sido desde el materialismo histórico desde donde se ha formulado el más fuerte alegato contra la biografía tradicional. Al contemplar la infraestructura económica como el condicionante fundamental de la vida de la sociedad, la actividad individual quedaba relegada a un segundo plano. Si son las masas quienes hacen la historia es inaceptable hacer de la vida de un hombre centro y eje de la investigación histórica. Sólo en la medida en que la actuación de un individuo se integra en el proceso de lucha de clases puede admitirse la biografía como género. Además el marxismo ortodoxo vio en la biografía muchas características que había denunciado como peligrosos desviacionismos de la conducta política. El subjetivismo, el voluntarismo, el individualismo (sobre todo bajo la forma de caudillismo), la tentación bonapartista del populismo, se contemplaron por el marxismo-leninista más riguroso como residuos indeseables tanto de una mentalidad burguesa (la desviación derechista), como de un utopismo aventurista (la desviación izquierdista). En la medida en que estos factores subyacen como elementos casi indisolubles de la biografía, quedaba ésta ya descalificada. A fin de cuentas la biografía ha sido uno de los géneros historiográficos favoritos de la interpretación whig de la historia, convencida de la capacidad de los individuos para modificar y transformar su medio social y a hacer de cada hombre un personaje capaz de actuar como motor o rémora del progreso histórico.

Al margen del hecho de que en sociedades regidas por los principios del marxismo se implantasen formas aberrantes de culto a la personalidad, es preciso reconocer que ha sido desde esta ideología desde donde con un más riguroso aporte dialéctico se ha atacado el fundamento epistemológico de la biografía. Y no puede olvidarse que si el marxismo como doctrina política ha quedado convertido en un referente histórico, como corriente de pensamiento no sólo ha influido, sino que se ha incorporado bajo formas muy diversas y sutiles en otras ideologías y por supuesto también en aquellas más contrarias a sus principios fundamentales.

La aparición de la llamada escuela francesa de los Annales fue la otra corriente historiográfica que más contribuyó a cuestionar la validez de la biografía. El grupo de historiadores que en torno a Lucien Febvre y Marc Bloch cristalizaron desde 1929 en la revista que ha dado nombre a la corriente, mostró una reticencia muy intensa ante el género. Especialmente por parte de Febvre se atacó duramente la llamada historia historizante, entre la que la biografía ocupaba un lugar destacado. Su finalidad no era otra que reunir los hechos a partir de los documentos, coordinarlos entre sí y luego exponerlos. Febvre, con su habitual capacidad para el sarcasmo, ironizó sobre quienes hacían historia a la manera como sus madres hacían tapices, es decir, al puntillo. 
Frente a este modelo se presentaba otro muchos más sugestivo, con un interés constante hacia aspectos olvidados por la investigación tradicional. Pasaron así a ocupar un lugar prioritario lo que Braudel ha llamado en uno de sus libros más ambiciosos las estructuras de lo cotidiano, es decir el estudio de la alimentación, las técnicas, los caminos, la transmisión de la cultura, los comportamientos demográficos 5 .

Los acontecimientos, la llamada histoire évenèmentielle, se convirtieron casi en objeto de burla, pues no serían más que una colección de hechos irrelevantes que distraerían al historiador de la auténtica realidad objeto de interés. El primer plano pasaban a ocuparlo las estructuras más invariables a través de un largo período de tiempo - la larga duración - que sí que condicionaban de forma decisiva las vidas de los individuos. El tiempo breve de la historia sería el más atendido por el historiador tradicional, aquel que según el mismo Braudel no se ocupaba más que de los acontecimientos y la biografía. Y el mismo autor resaltaba que el tiempo corto es el que interesa sobre todo a los periodistas, cuando es el que mayor rechazo provoca entre la historia social porque es el más caprichoso y engañoso. En los Annales ejerció una influencia decisiva el marxismo, hasta el punto de que en la década de los sesenta algunos consideraban que aquella forma inicial de hacer historia se había visto «usurpada, en sus ambiciosos planteamientos, por un estricto materialismo de cuño marxista, que tiende a potenciar, como fuerza neutralizadora de cualquier otra en la evolución de la historia humana, la encarnada por los factores económicos». Es preciso reconocer también la indiscutible seducción del programa de esta corriente historiográfica que ha afectado a la misma historiografía más declaradamente marxista, aun cuando algunos, como Josep Fontana, no vean en la corriente más que un pensamiento oportunista, ecléctico y entregado hipócritamente a la reacción bajo un ropaje metodológico supuestamente moderno y por tanto totalmente alejado del marxismo.

La biografía se vio inevitablemente atenazada en este proceso. Se hizo habitual el desaconsejar a los historiadores noveles que iban a comenzar una tesis la elección de temas biográficos. En el mundo académico, tan preocupado siempre por la promoción y la exclusión de quien se supone no se mueve en las corrientes más a la moda, la biografía quedó casi proscrita. El hecho ha tenido consecuencias lamentables cuando se ha contemplado el modelo francés como el ejemplo a imitar. No puede ignorarse que la historiografía francesa tenía una brillantísima tradición en la línea más positivista, más atenta a la

5 Braudel, F. (1984), Civilización material, economía y capitalismo. Siglos XV-XVIII, Madrid. 
verificación del hecho, que llevaba decenios frecuentando los archivos en una casi fetichista búsqueda de datos y desde luego declaradamente historizante. Los historiadores de los Annales se han servido de estos materiales sin ningún empacho para, sobre sus hallazgos, construir muchos de sus más brillantes escritos, al margen de los dicterios que les hayan podido dedicar cuando se detienen en la reflexión teórica sobre su oficio.

El problema ha tenido otra dimensión cuando esos criterios se han trasplantado a países sin esa brillante tradición positivista. Entonces se ha puesto de manifiesto la existencia de vacíos que no es posible salvar más que con peligrosas elipsis, o lo que es peor, manteniendo interpretaciones que se deshacen al menor contacto con la rotunda evidencia de un documento de archivo. En el ámbito geográfico español, de tradicional influencia francesa, este hecho ha sido muy evidente y así hemos llegado a una situación llena de ambigüedades y dobles mensajes. Por un lado mientras se hacen públicas declaraciones de aceptación de los principios de la «nueva historia», se publican incesantemente repertorios y catálogos que inevitablemente tienen que suplir deficiencias que en otros países se habían resuelto antes de 1920. En el ámbito de la biografía sucede algo similar. Mientras la historiografía francesa cuenta desde el siglo XIX con monografías y diccionarios biográficos que cubren un amplísimo abanico de la sociedad francesa y que hace posible reinterpretaciones y revisiones impensables sin esa previa tarea de recopilación, en los países meridionales (España, Portugal, en menor medida Italia) se carece de aportaciones similares, con lo que el investigador se ve constantemente obstaculizado en su investigación por la deficiencia de informaciones que son, al margen de cualquier otra consideración, sencillamente fundamentales. Todos sabemos lo difícil que en tantas ocasiones resulta determinar las fechas de nacimiento o muerte de un autor, la universidad donde obtuvo su gradación o elementales noticias de su carrera profesional imprescindibles para definir una trayectoria vital. Y lamentablemente sólo algunos colectivos han recibido una atención sistemática de la administración civil o eclesiástica como para que sus expedientes personales, en forma de hojas de servicios o de memoriales reivindicativos de una merced o un puesto, permitan llevar a cabo estudios sistemáticos sobre su origen social, formación, promoción, movilidad social y geográfica, relaciones mutuas y medio familiar.

En el mundo anglosajón la situación ha sido muy distinta, porque el empirismo ha ejercido también en la historiografía una fuerte presión. Además ha existido una aceptación mucho más generalizada de los principios del liberalismo como hemos advertido antes y en consecuencia un mayor reconocimiento de las posibilidades del individuo frente a la sociedad. Es lógico que 
allí donde la iniciativa privada es contemplada como supremo motor social, la biografía se haya visto con ojos muy distintos a los de países donde se busca en otros ámbitos más alejados de la órbita personal la solución y reforma de los problemas sociales. Simultáneamente la presión de la ideología de izquierda ha entrado en crisis y ha gozado de menor influjo. El resultado se ha advertido en la biografía a través de un mayor desarrollo del género entre los historiadores. Todavía en 1986 Chaussinand-Nogaret reconocía que la biografía, que florecía en los países anglosajones, había sido descuidada en Francia por los historiadores y abandonada en otras manos ${ }^{6}$. Igualmente es muy significativo que en el XVII Congrés International des Sciences Historiques celebrado en Madrid en 1990 las aportaciones a la ponencia metodológica sobre la biografía procedían fundamentalmente de historiadores más cercanos a la órbita anglosajona. Y en una revisión para esta intervención realizada sobre la base de datos que constituye el Historical Abstract, las aportaciones teóricas recogidas en las palabras clave «biografía-metodología» recogen valoraciones más positivas desde la cultura germana y anglosajona, mientras son mucho más escasas y en cualquier caso más reticentes en el mundo de habla francesa. Precisamente desde 1988 en Alemania y a través de la revista Bios se vienen produciendo las aportaciones más sustanciales a los problemas metodológicos de la biografía como relato y a la historia oral en su doble condición de experiencias personales del propio informante y de testimonio ilustrativo sobre el individuo objeto de la investigación.

\section{LA BIOGRAFÍA Y LA ACADEMIA}

La desaparición de estas reservas ha contribuido muy decisivamente a que también en el ámbito académico se haya producido una revitalización de los estudios centrados en un individuo como tema u objeto de una tesis doctoral ${ }^{7}$. Como inicio en la investigación el estudio de un individuo plantea desde un

6 Chaussinand-Nogaret, G. (1986), «Biographique». En BurguiéRe, A., Dictionnaire de sciences historiques, Paris.

7 El lector curioso puede comprobar el cambio producido consultando los volúmenes Tesis Doctorales publicados por el Consejo de Universidades empleando como fuente informativa la base de datos TESEO, así, en los trece años comprendidos 1976 y 1989, se contabilizaban una media de cuatro tesis por curso académico, mientras en el curso 1989-1990 esa cifra se eleva a 12 (sin incluir las tesis de historia por disciplinas que incrementa aún más este número, ni tampoco las defendidas en historia del arte o de la literatura por las peculiaridades de estos saberes). 
punto de vista heurístico todos los retos y dificultades de la investigación histórica atemperados, sin embargo, por la imprescindible delimitación temporoespacial que determina el mismo personaje como eje vertebrador de la investigación. Al mismo tiempo ofrece oportunidades constantes para adentrarse en el estudio de numerosos problemas que surgen en el curso de la investigación. Es preciso pues recordar que un estudio histórico vertebrado sobre un personaje no puede limitarse a la simple transcripción de documentos de archivo relativos al personaje, por novedosos que éstos sean. El mayor peligro reside precisamente en la seducción que el personaje acaba siempre por producir al historiador y el riesgo de que su investigación se convierta en una apología o en una diatriba. Pues en efecto la denuncia tradicional que se ha hecho de la biografía como género que desemboca con frecuencia en una hagiografía edulcorada del personaje, mantiene su vigencia también ante las de signo contrario, cuando la desmitificación del personaje es pretexto para un proceso de demonización igualmente censurable. La biografía iconoclasta tiene también unos límites de equilibrio y distanciamiento que no deben superarse.

Sin embargo es preciso señalar que las objeciones que tradicionalmente se han puesto a los estudios biográficos siguen levantándose hoy como un obstáculo cuya superación no siempre resulta fácil. Sin duda el problema fundamental sigue siendo articular la trayectoria vital del personaje con el contexto social en que lleva a cabo su actividad. Establecer en definitiva las conexiones entre los acontecimientos externos y la actividad pública que llenan de episodios la vida del individuo, con los procesos mentales y las vivencias íntimas que conforman su pensamiento y su específica manera de enfrentarse a la realidad circundante. En definitiva ese ideal representado en el título convencional de «el personaje y su tiempo», tantas veces fracasado por limitarse a una mera reproducción de anécdotas o a una revisión del entorno social en que el sujeto queda diluido u oculto. En un estudio ya clásico Seco Serrano hacía de este problema el escollo fundamental de la biografía como género historiográfico y es preciso señalar la vigencia de este diagnóstico ${ }^{8}$. La cercanía temporal impide muchas veces por pudor o prudencia integrar en el estudio biográfico aspectos de la dimensión más personal del sujeto que no se considera oportuno dar a conocer. Es significativo que Seco propusiese en su día como «modelo» de biografía que cumplía a satisfacción ese ideal, el Cambó de Pabón, un estudio en tantos aspectos ejemplar, pero donde las actividades económicas del político eran silenciadas y su vida familiar parecía inexistente. No se puede caer ni en la triviali-

8 Seco Serrano, C. (1976), «La biografía como género historiográfico», en Once ensayos sobre la historia, Madrid, 107-117 
dad ni en la narración de cotilleos, pero tampoco se puede eludir en un estudio biográfico la presentación de aspectos de la vida íntima del personaje que condicionan muchas actuaciones de su vida pública9.

El enfrentamiento del hombre con el grupo se presenta también ahora como un problema que poco tiene que ver con la trasnochada polémica sobre las personalidades singulares en la historia. En efecto, la relación del individuo con los colectivos en cuyo seno desenvuelve su actividad, exige analizar la forma en que esos grupos vinculados por la profesión, la procedencia geográfica, la comunidad de estudios o la ideología política o religiosa, establecen redes clientelares y de intereses que no siempre es fácil identificar ni relacionar. Una biografía ambiciosa supera y desborda la mera significación del personaje, para convertirse en realidad en el retrato de toda una generación, de todo un grupo social, de toda una época. Mantener el equilibrio entre lo personal y lo circundante de modo que la iniciativa del sujeto no quede asfixiada por el entorno es otro de los problemas a superar.

Hay en la biografía, en fin, un elemento irreductible de cada individuo que se encuentra en su intimidad y que resulta del todo inasible y contradictorio, que se levanta siempre como el obstáculo más difícil para el historiador. Por eso en la biografía más que en ningún otro género historiográfico es su autor, más aún que el propio personaje, quien acaba constituyéndose en referente fundamental de nuestra comprensión del personaje. El autor es quien dispone y jerarquiza no sólo los acontecimientos que considera relevantes, sino quien establece las relaciones de causalidad que de una u otra manera definen una trayectoria vital. Y aquí es preciso señalar como por ser la biografía una de las formas de hacer historia más inevitablemente narrativa, es donde la elección del procedimiento expositivo tiene una mayor importancia. Aun cuando la cronología y la sucesión temporal de los hechos sean siempre el eje vertebrador del relato, los planos en que se presenta la reconstrucción de una vida ofrecen diversas posibilidades. Desde luego por lo anteriormente comentado la mera secuencia cronológica es válida únicamente en las formas más elementales del estudio biográfico: la nota breve, las colecciones acríticas de hechos o los estudios introductorios a escritos ${ }^{10}$. La elección de una presentación de la

9 Dos estudios realizados por un mismo autor, Alvarez Junco, muestran el mayor predominio de lo personal e íntimo en uno (Diego Hidalgo. Memoria de un tiempo difícil, Madrid, 1986) mientras en otro (El emperador del Paralelo: Lerroux y la demagogia populista, Madrid, 1990) el medio social domina toda la narración

10 Muy didáctica resulta la clasificación de estudios biográficos de Engelberg y Schleier: $1^{\mathrm{o}}$ Nota breve, $2^{\circ}$ Colecciones acríticas de hechos (vida y escritos), $3^{\circ}$ Crítica histórica de las 
biografía en función de las facetas del biografiado con mayor proyección social (política, milicia, docencia, investigación) o atendiendo más a etapas profesionales desarrolladas en un espacio de tiempo concreto y dotadas por tanto de una cierta unidad cronológica, condicionan desde luego el propio discurso. En otros casos, y precisamente para evitar todas esas limitaciones y para superar también unos convencionalismos que se considera caducados, se elige una exposición en planos de tal manera que se opta por ir de lo más general (estructuras sociales, organización económica, vida cotidiana), a lo más personal (el individuo, sus relaciones, sus ideas y aficiones) en que la conexión de ambas realidades se muestra al lector a través de los acontecimientos que configuran el presente. Un esquema en fin que no hace más que trasladar, a la biografía el proceder expositivo que Braudel y sus seguidores hicieron habitual en tantas monografías ya clásicas ${ }^{11}$.

Es menester señalar que hoy, a pesar de la superación de tantas reticencias del pasado estos problemas se siguen presentando como «cuestiones disputadas», por utilizar la terminología escolástica con que las define un autor reciente $^{12}$. La presencia del llamado paradigma moderno de la biografía, atento al individuo como personaje y reivindicador de la máscara como superación de la figura ejemplificante, tiene riesgos que el historiador no puede desconocer. La biografía como escritura sigue siendo poner orden en una vida para hacerla comprensible. Y en ese intento las contradicciones del personaje se confunden inevitablemente con las del propio historiador ${ }^{13}$.

características personales, $4^{\circ}$ Ensayo bibliográfico o introductorio a escritos, $5^{\circ}$ Autobiografía, $6^{\circ}$ Biografías espirituales o comprensivas, $7^{\circ}$ Biografías literarias, $8^{\circ}$ Biografías psicoanalíticas, $9^{\circ}$ Prosopografías, $10^{\circ}$ Historia oral. Engelberg, E.; Schleier, H., (1992), «The contribution made by Historical Biographies of the $19^{\text {th }}$ Century Towards deeping Historical Biography», 17 Congreso Internacional de Ciencias Históricas, Madrid, II, 1105-1109.

11 Es el modelo expositivo elegido por Fernández Alvárez en sus biografías sobre Felipe II o Carlos V, en que la época, los acontecimientos y el hombre se convierten en los tres niveles narrativos sobre los que se estructura la biografía del rey.

12 PeÑa PÉReZ, F.J. (2002), «El renacimiento de la biografía», Edad Media. Revista de Historia, 5:39-66.

13 Madelenat, D. (1984), La biographie, Paris, 63 y ss. 